\title{
World's ocean drillers plan for decade of technological change
}

Washington

The Ocean Drilling Program (ODP) is gradually changing course as more sophisticated technology provides new opportunities for experiments and new ideas about the Earth's evolution demand more sophisticated technology to run bigger scale experiments. So much emerges from a meeting of the world's ocean drillers held in Strasbourg last week to try to define the overall objectives for the ODP in the 1990 s.

The Second Conference on Scientific Ocean Drilling (COSOD II) comes a full six years after the first. Day-to-day management of the programme rests with the Texas A\&M University, with overall planning provided by the Joint Oceanographic Institutions for Deep Earth Sampling (JOIDES), an international body that represents the US, Canadian, French, British, West German, Japanese and European organizations that support ODP. Only occasionally is the need felt to assemble the world community to try to reach agreement on the larger framework within which individual projects will be planned.

Recommendations will be made early next year after five working groups (for global environmental change, mantle/ crust interactions, fluid circulation and global chemical budgets, brittle and ductile transformation of the lithosphere, and evolution and extinction of oceanic biota) have revised their proposals and met once more. But it is already clear that everyone's research needs can be met only if the programme goes in two different directions at once.

Some, particularly those studying global environmental changes and evolution and extinction, need breadth rather than depth. They want to construct global maps embodying variation in the sedimentary record in space, time and depth to tell how ocean, atmosphere and biota respond to change. That need can best be met by a ship capable of going around the world (including even polar regions), and piston coring of ocean sediments.

But other groups, particularly that looking at mantle/crust interactions, want depth rather than breadth. Although sympathetic to the palaeo-oceanographers desires to "collect a world library of mud", the mantle/crust researchers emphasized at Strasbourg the need to develop the technology for drilling deep holes. The aim is to get a 6-7 km deep hole down to the Mohorovičić discontinuity (Moho) within the next 15 years. Other groups would also like to be able to drill deep in difficult places, have the capacity to stay on one station for months and to re-enter a hole several years later. The fluid circulation group, for example, would like to have data from inside an active hydrothermal system. The necessary advances

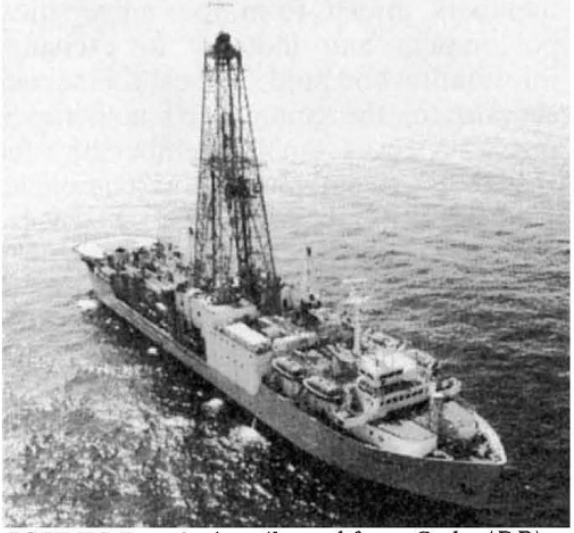

JOIDES Resolution (leased from Sedco/BP).

in drilling technology are difficult, but do not appear impossible.

Although no programme could possibly meet every wish expressed at the meeting, a massive leap forward could be made if there were a second vessel to handle the

less technically demanding needs. The JOIDES Resolution drill ship is very sophisticated and using it for collecting sedimentary cores can be compared to "using a Rolls-Royce when a minibike would do", according to one researcher.

A second ship has usually been thought of as just a dream - but, according to US researchers, French scientists seem convinced the dream can be made real. A budget increase of somewhere between 10 and 50 per cent will be needed, which it is hard to see coming from the United States, already by far the largest contributor. US scientists hope that Europe can provide the necessary push.

Organization is another issue. The present routine, in which the ship voyages around the world visiting a variety of regions, reflects an organizational structure in which five regional panels have considerable say. A sustained effort requiring long periods at one location would be hard to sell. For this reason, and because many feel that there is a need to move from an 'exploration mode' to an 'experimental mode' in which specific hypotheses are tested, there may be a gradual shift towards clearer definition of goals with project managers coordinating drilling on many different legs.

Alun Anderson

\section{French Earth science policy set for radical shake-up}

Paris

EARTH sciences research in the Centre Nationale de la Recherche Scientifique (CNRS), France's leading science research body, has been radically shaken up by a decision that all future studies should be concentrated on a limited number of major questions.

This initiative, the brainchild of Claude Allègre, formerly director of the Institut de Physique du Globe (IPG) in Paris and now director of its geochemistry laboratory, aims to move away from the previous CNRS strategy of Actions Thématiques Programmés (ATPs), in which research was focused on specific topics in each discipline, usually for five years. Instead, there will be a simpler administrative procedure with perpetual priorities.

By abandoning the ATP principle, whose themes were beginning to appear arbitrary, Allègre hopes to "aim at more fundamental problems, such as instability or global transfer, and to apply the approach of geophysics and geochemistry to surface phenomena such as erosion and sedimentation".

Two programme areas have been established, each with its own selection committee. The first, entitled Imaging and Structure of the Earth (IST) and chaired by Jean Auboin, professor of structural geology at the University of Paris VI, will include seismic imaging of the Earth's interior, crustal imaging and satellite-based imaging.

The second programme, chaired by Allègre himself, will deal with the Dynamics and Budgets of the Earth (DBT), and will have ten major headings: ocean budgets (which, for the first two years, will concentrate on the influences of the world's 20 major rivers), mechanisms of erosion, sedimentation and sea-level change, continental growth, global Earth coupling, instability phenomena in the Earth's crust, remagnetization and its importance for palaeomagnetism, rifting and kinetics of geochemical reactions.

As well as restricting the themes that will be supported, Allègre wants the bulk of the research to be tackled by a small number of 'centres of excellence', with the aim of reducing by one-third the number of projects supported and encouraging smaller groups to associate themselves with larger ones.

Allègre stressed that this should not be interpreted as a 'lame duck' policy. "We are talking only about programme money, not running costs or salaries. Laboratories that do not want to take part will still be able to get along."

Peter Coles 